\title{
Extralymphatic disease due to bancroftian filariasis
}

G. Dreyer ${ }^{1,2}$

P. Dreyer and

W.F. Piessens ${ }^{3}$
1Departamento de Parasitologia, Centro de Pesquisas Aggeu Magalhães (CPqAM), Fundação O swaldo Cruz, and ${ }^{2}$ Núcleo de Ensino Pesquisa e Assistência em Filariose (NEPAF), Hospital das Clínicas, Universidade Federal de Pernambuco, Recife, PE, Brasil ${ }^{3}$ Department of Immunology and Infectious Diseases, Harvard School of Public Health, Boston, MA, USA

\section{Correspondence}

G. Dreyer

NEPAF, Hospital das Clínicas

Universidade Federal de Pernambuco

Av. Prof. Moraes Rego, s/n

50670-901 Recife, PE

Brasil

Fax: + 55-81-427-6455

Received July 5, 1999

Accepted November 8, 1999

\section{Abstract}

Infection with Wuchereria bancrofti, Brugia malayi, or B. timori not only affects the structure and function of lymphatic vessels but is also associated with extralymphatic pathology and disease. Because it is now possible to detect living adult worms by ultrasonography, much emphasis is placed on lymphatic pathology. However, the finding of renal damage in asymptomatic microfilaremic carriers has led to increased recognition of the importance of extralymphatic clinical manifestation in bancroftian filariasis. The authors present a number of clinical syndromes that may be manifestations of extralymphatic filarial disease and discuss possible mechanisms that cause these conditions. The main purpose of this paper is to raise the awareness of students and physicians of the prevalence and the importance of extralymphatic disease in bancroftian filariasis so that it is diagnosed and treated properly and also to alert for the need of additional research in this area.

\section{Introduction}

Lymphatic filariasis persists as a major cause of clinical morbidity and a significant impediment to socioeconomic development in Asia, Africa and the Western Pacific, as well as in certain regions of the Americas. It is estimated that at least 120 million persons are infected with $W$. bancrofti and B. malayi. Of these, 40 million patients suffer from lymphedema, elephantiasis or hydroceles the well-known clinical manifestations of lymphatic disease (1).

Recently, dramatic advances in our understanding of the pathogenesis of this disease have led to the recognition that subclinical lymphatic damage is present in all in- fected patients. Lymphatic dysfunction resulting from this damage predisposes to local microbial infection, which in turn exacerbates lymphatic pathology (2-5). However, little attention has been paid in recent years to clinical manifestations of extralymphatic disease caused by filariasis. This paper summarizes the current knowledge about this topic. It is intended to reemphasize the importance of extralymphatic morbidity in bancroftian filariasis, and to highlight the gaps in our knowledge of the pathogenic mechanisms that underlie the various clinical syndromes.

The extralymphatic syndromes resemble clinical entities of nonfilarial origin, and it is often impossible to establish with absolute 
certainty the filarial etiology of extralymphatic disease manifestations in an infected individual. Similar diagnostic uncertainties also apply to some of the "classical" manifestations of lymphatic filariasis $(4,5)$. Unlike lymphatic disease syndromes, the extralymphatic manifestations of bancroftian filariasis are not caused by adult worms per se, but by microfilariae, by diffusible products from as yet undefined parasite stages, or by immune complexes. Extralymphatic filarial disease is thus heterogeneous in its pathogenesis and clinical manifestations.

\section{Arthritis}

Arthritis has long been recognized as a possible manifestation of filarial infections (6). Two clinical types have been described. The first is oligoarticular "filarial arthritis", a rare condition that typically affects just one large joint, most commonly a knee. The entity can be distinguished from other forms of arthritis by clinical criteria associated with laboratory findings and by its prompt response to diethylcarbamazine (DEC) (7). Its pathogenesis is unclear. Synovial fluid from the affected joint ordinarily does not contain microfilariae, adult worms or pyogenic organisms, but the monoarticular inflammation may reflect a tissue reaction to a filarial worm in the vicinity of the joint. Rarely, lymphatic fistulation into the synovial sac causes chylous arthritis (8).

The second manifestation, polyarticular "filarial pseudo-rheumatism", appears to be less common in lymphatic filariasis than in onchocerciasis, loiasis or mansonellosis. Its pathogenesis is believed to involve intraarticular deposition of immune complexes (9). However, immune complexes containing filarial antigens have yet to be detected in synovial tissue, and they are present in sera from many infected patients without arthritis $(10,11)$. Intact microfilariae have been detected intra-articularly in some patients with filarial polyarthritis and in animals (12). In such cases, local release of proteases by the worms (13) may directly damage synovial tissue.

\section{Renal disease}

Despite case reports over the years describing instances of glomerulonephritis, hematuria and proteinuria in patients with filarial infections, the prevalence of renal abnormalities in bancroftian filariasis has only recently been formally determined. Renal disease is rarely observed in patients without microfilaremia. In contrast, $\sim 45 \%$ of untreated microfilaremic patients have renal pathology manifested as microscopic hematuria $(\sim 35 \%)$ and/or proteinuria $(\sim 20 \%)$. Treatment with DEC exacerbates the proteinuria in these patients and also triggers transient hematuria or proteinuria in many microfilaremic persons with a normal urine analysis prior to treatment (14). Mechanical damage to glomeruli by circulating microfilariae is believed to account for hematuria in some cases $(15,16)$, but damage caused by deposition of immune complexes in the glomerular basement membrane is likely to be a far more common cause of renal pathology in bancroftian filariasis. Such complexes have been observed in renal biopsies of patients with filarial infections and glomerulonephritis (17-19). However, only in patients with onchocerciasis has it been formally determined that antigens within immune complexes deposited in the kidneys are of filarial origin (20).

\section{Tropical pulmonary eosinophilia}

Several helminth species can cause pulmonary infiltrates and eosinophilia (PIE), a transient syndrome resulting from the migration of worms through the organ (21). Filarial worms most often cause a lingering variant of PIE known as tropical pulmonary eosinophilia (TPE) (22-24). TPE occurs in only a small percentage of patients (mostly 
males) with bancroftian filariasis $(25,26)$, and nonfilarial helminths can cause a similar clinical syndrome (27).

Filarial TPE is a syndrome clinically characterized by symptoms of bronchial asthma with paroxysmal nocturnal cough and anorexia. Pulmonary function tests reveal restrictive and obstructive lung disease. Interstitial lung disease is believed to result from immune hyperreactivity to microfilaria. Microfilariae are trapped and destroyed in the lung by antibody-dependent, cell-mediated cytotoxicity involving eosinophils (28). This triggers an inflammatory process that evolves over time. Degenerating worms release somatic allergens that bind to specific cellbound $\operatorname{IgE}$ and thereby trigger the release of vasoactive and inflammatory molecules by lung basophils and mast cells. These mediators cause some of the allergic asthma-like manifestations of TPE. Many empirical and experimental observations are consistent with this model. Microfilariae or recognizable fragments are present in lung nodules from patients with TPE and thus may serve to trigger and focus the pathogenic process (29). Most postulated effector cells and molecules are present in lower respiratory tract epithelial lining fluid, i.e., at the site of the lesions $(30,31)$.

Microfilariae are a primary trigger of lung disease in the pathogenic scheme just described: the continuous arrival in the lungs of new microfilariae produced by living adult worms located elsewhere and identified by ultrasonography (27) provides the stimulus that guarantees the chronicity of the clinical syndrome. However, the effector mechanisms that damage lung parenchyma are not yet completely known. Possibilities include immune complex deposition, eosinophil-mediated injury to parenchymal cells and the interstitial matrix (32), cytokine-mediated cell injury and other so-called bystander effects, as well as possible autoimmune reactions triggered by crossreactivity between filarial and human collagens (33). Alterna- tively, factors released into the general circulation by filarial worms lodged in extrapulmonary lymph vessels may act on lung epithelial cells and cause airway hyperreactivity and/or tissue damage (34). The lung is the main organ affected by TPE, but extrapulmonary lesions such as hepatosplenomegaly and lymphadenopathy can occur (23). Cardiovascular involvement in TPE has been reported (35-38). Because the electrocardiographic changes suggestive of ischemic heart disease are reversed following treatment with $\mathrm{DEC}$, it is assumed that carditis is of filarial etiology. This may not be true, however, because in addition to being an antihelminthic, the drug has anti-inflammatory, antimicrobial, antifungal and antiviral properties (39-42).

TPE is the best known clinical manifestation of occult filariasis (43). Destruction of microfilariae in organs other than the lung can cause several other clinical entities. Bonne (44) reported the presence of microfilariae and hypereosinophilia in the spleen, but not in other internal organs, of a man who died a violent death. The histological changes in the spleen were similar to those described by Meyers and Kouwenaar (23) in lymph nodes from patients with TPE.

The relationship between filarial worms and tropical endomyocardial fibrosis (TEMF) remains unclear. The geographic distribution of TEMF overlaps with that of TPE in India and with loiasis in Africa, suggesting that eosinophils induced and activated by filarial infections may cause the observed endomyocardial changes (45). Eosinophils have two main functions: they can inactivate many of the mediators released by mast cells and thereby dampen tissue reactions associated with IgE-mediated degranulation of mast cells. When activated by antibodies or by complement, they can also damage the larval stages of some helminths and kill a variety of cell types. The damage is inflicted by the deposition of the contents of the eosinophilic granule, especially the major basic 
protein (MBP), on the surface of the target worm or cell. It has been suggested that MBP release may partly account for the tissue damage observed in conditions of local hypereosinophilia such as TEMF. Whether this has any relevance to the cardiac changes seen in TPE is unknown, but eosinophils from patients with TPE are partly degranulated in vivo (46).

\section{Microfilarial granulomata}

Circumscribed granulomata containing microfilariae have been observed in the spleen or occasionally in other organs $(47,48)$. However, considering the large number of microfilariae present in most infected individuals, microfilarial granulomata are extremely uncommon and rarely cause clinical illness (49).

\section{Filarial splenomegaly}

The spleen is not usually involved in bancroftian or brugian filariasis although splenomegaly occurs in experimentally infected animals. Single-dose DEC treatment reduced splenomegaly in residents of an area of Papua New Guinea where bancroftian filariasis and malaria are co-endemic, a finding consistent with the notion that filarial infection associated with malaria resulted in higher spleen rates and sizes (50). This does not establish a causal relationship between $W$. bancrofti and splenomegaly because DEC has many properties besides being an antihelminthic (see above). Further, reduction of splenomegaly in patients with concomitant filariasis and malaria can be achieved by treatment with antimalarials without associated DEC (51).

\section{Skin rashes}

Transient urticarial skin rashes and nonsuppurative swellings without signs of acute inflammation were observed in World War
II military personnel in the South Pacific $(52,53)$ and in human volunteers infected with $B$. malayi (54), but appear to be rare in native residents (55). Pathological changes in biopsies from transient rashes in World War II soldiers are consistent with an allergic reaction (56) and markedly differ from the inflammatory reactions observed in the skin of patients with chronic lymphedema (3). Some consider these fugitive rashes to be the equivalents of Calabar swellings (52), i.e., transient areas of angioedema thought to result from an allergic response to Loa loa products. Of interest, loiasis in temporary residents also often presents with increased severity and frequency of pruritus, urticaria and Calabar swellings compared to the native population (57). Thus, immune reactions to filarial worms in immigrants qualitatively and quantitatively differ from those in native residents, perhaps because the latter develop pre- or perinatal immune tolerance to worm antigens $(58,59)$.

\section{Final considerations}

Infection with lymphatic filarial parasites is associated with a remarkably wide range of clinical signs, symptoms and sequelae. Because adult worms are considered to be the main parasite stage responsible for clinical manifestations of the infection, the importance of extralymphatic disease manifestations has been underrated in the past. The recent recognition that renal damage (mainly with microscopic hematuria) is present in $30 \%$ of asymptomatic male microfilaremic carriers (14) clearly shows that the real extralymphatic morbidity might be underestimated worldwide. Hence, as long as the lymphatic filariasis elimination program (60) is not completed and microfilariae are not eliminated from carriers, it is advisable that additional studies be conducted in order to improve our knowledge of extralymphatic disease in endemic areas of lymphatic filariasis. 


\section{References}

1. WHO - World Health Organization (1994). Lymphatic filariasis infection and disease: Control strategies. WHO/CTD/TDR document.

2. Norões J, Addiss D, Santos A, Medeiros Z, Coutinho A \& Dreyer G (1996). Ultrasonographic evidence of abnormal lymphatic vessels in young men with adult Wuchereria bancrofti infection in the scrotal area. J ournal of Urology, 156: 409-412.

3. Olszewski WL, Jamal S, Manokaran G, Lukomska B \& Kubicka U (1993). Skin changes in filarial and non-filarial lymphoedema of the lower extremities. Tropical Medicine and Parasitology, 44: 40-44.

4. Dreyer G, Medeiros Z, Netto MJ , Leal NC, De Castro LG \& Piessens WF (1999). Acute attacks in the extremities of persons living in an area endemic for bancroftian filariasis: differentiation of two syndromes. Transactions of the Royal Society of Tropical Medicine and Hygiene, 93: 1-5.

5. Dreyer G \& Piessens W (1999). Worms and microorganisms can cause lymphatic disease in residents of filariasis-endemic areas. In: Nutman TB (Editor), Lymphatic Filariasis. Imperial College Press, London, 239-256.

6. Maitland J (1898). On some of the less common manifestations of filariasis. Indian Medical Gazette, 33: 321-2s-361-2s.

7. Ismail MM \& Nagaratnam N (1973). Arthritis, possibly due to filariasis. Transactions of the Royal Society of Tropical Medicine and Hygiene, 67: 405-409.

8. Das GC \& Sen SB (1968). Chylous arthritis. British Medical J ournal, 2: 27-29.

9. Doury $P$, Pattin $S$, Dienot $B$, Roue $R \&$ Delahaye RP (1977). Les rhumatismes parasitaires. Semaine des Hopitaux de Paris, 53: 1359-1363.

10. Au AC, Denham DA, Steward MW, Draper CC, Ismail MM, Rao CK \& Mak J W (1981). Detection of circulating antigens and immune complexes in feline and human lymphatic filariasis. Southeast Asian J ournal of Tropical Medicine and Public Health, 12: 492-498.

11. Dissanayake S, Galahitiyawa SC \& Ismail MM (1982). Immune complexes in Wuchereria bancrofti infection in man. Bulletin of the World Health Organization, 60: 919-927.

12. Weinberger A, Schumacher HR \& Weiner DJ (1979). Intraarticular microfilariae in laboratory animals. Arthritis and Rheumatism, 22: 1142-1145.

13. Petralanda I, Yarzabal L \& Piessens WF
(1986). Studies on a filarial antigen with collagenase activity. Molecular and Biochemical Parasitology, 19: 51-59.

14. Dreyer G, Ottesen EA, Galdino E, Andrade L, Rocha A, Medeiros Z, Moura I, Casimiro I, Beliz F \& Coutinho A (1992). Renal abnormalities in microfilaremic patients with bancroftian filariasis. American J ournal of Tropical Medicine and Hygiene, 46: 745751.

15. Stenhouse HM (1925). Renal pathology in filariasis bancrofti. United States Naval Medical Bulletin, 22: 1-12.

16. Mukherjee SK, Mukherjee AK \& Sen JK (1974). Filariasis with recurrent hematuria. J ournal of the American Medical Association, 230: 1254-1255.

17. Date A, Gunasekaran V, Kirubakaran MG \& Shastry JC (1979). Acute eosinophilic glomerulonephritis with bancroftian filariasis. Postgraduate Medical J oumal, 55: 905-907.

18. Date A, Neela P \& Shastry JC (1983). Membranoproliferative glomerulonephritis in a tropical environment. Annals of Tropical Medicine and Parasitology, 77: 279-285.

19. Yap HK, Woo KT, Yeo PP, Chiang GS, Singh M \& Lim CH (1982). The nephrotic syndrome associated with filariasis. Annals of the Academy of Medicine, Singapore, 11: 60-63.

20. Ngu J L, Chatelanat $F$, Leke $R$, Ndumbe $P$ \& Youmbissi J (1985). Nephropathy in Cameroon: evidence for filarial derived immune-complex pathogenesis in some cases. Clinical Nephrology, 24: 128-134.

21. Crofton J W, Livingstone J L, Oswald NC $\&$ Roberts TM (1952). Pulmonary eosinophilia. Thorax, 7: 1-35.

22. Danaraj TJ , Pacheco G, Shanmugaratnam K \& Beaver PC (1966). The etiology and pathology of eosinophilic lung (tropical eosinophilia). American J ournal of Tropical Medicine and Hygiene, 15: 183-189.

23. Meyers FM \& Kouwenaar W (1939). Over hypereosinophilie en over een merkwaardigen vorm van filariasis. Geneeskundig Tijdschrift voor Nederlandsch-Indie, 79: 853-873.

24. Weingarten RJ (1943). Tropical eosinophilia. Lancet, 1: 103-105.

25. Magnussen $P$, Makunde $W$, Simonsen $P E$, Meyrowitsch $D \&$ J akubowski $K$ (1995). Chronic pulmonary disorders, including tropical pulmonary eosinophilia, in villages with endemic lymphatic filariasis in Tanga region and in Tanga town, Tanzania. Transactions of the Royal Society of
Tropical Medicine and Hygiene, 89: 406409.

26. Dreyer G, Norões J , Rocha A \& Addiss D (1996). Detection of living adult Wuchereria bancrofti in a patient with tropical pulmonary eosinophilia. Brazilian J oumal of Medical and Biological Research, 29: 1005-1008.

27. Rocha A, Dreyer G, Poindexter RW \& Ottesen EA (1995). Syndrome resembling tropical pulmonary eosinophilia but of nonfilarial aetiology: serological findings with filarial antigens. Transactions of the Royal Society of Tropical Medicine and Hygiene, 89: 573-575.

28. Ottesen EA \& Nutman TB (1992). Tropical pulmonary eosinophilia. Annual Review of Medicine, 43: 417-424.

29. Danaraj TJ (1959). Pathologic studies in eosinophilic lung (tropical eosinophilia). American Medical Association. Archives of Pathology, 67: 515-524.

30. Nutman TB, Vijayan VK, Pinkston $P$, Kumaraswami V, Steel C, Crystal RG \& Ottesen EA (1989). Tropical pulmonary eosinophilia: analysis of antifilarial antibody localized to the lung. J ournal of Infectious Diseases, 160: 1042-1050.

31. Pinkston $P$, Vijayan VK, Nutman TB, Rom WN, O'Donnell KM, Cornelius MJ, Kumaraswami V, Ferrans V], Takemura T, Yenokida G, Thiruvengadam KV, Tripathy SP, Ottesen EA \& Crystal RG (1987). Acute tropical pulmonary eosinophilia. Characterization of the lower respiratory tract inflammation and its response to therapy. J ournal of Clinical Investigation, 80: 216-225.

32. Davis WB, Fells GA, Sun XH, Gadek JE, Venet A \& Crystal RG (1984). Eosinophilmediated injury to lung parenchymal cells and interstitial matrix. J ournal of Clinical Investigation, 74: 269-278.

33. Petralanda I \& Piessens WF (1991). Onchocerca volvulus, O. gutturosa, Brugia malayi, and Dirofilaria immitis: A comparative study of the immunochemical properties of cuticular proteins from filarial parasites. Experimental Parasitology, 72: 164173.

34. Maya A, Usha S, J ayaraman K, Baba K, Sukumaran M \& Balakrishnan A (1995). Interaction of filarial proteins on growth regulation of normal lung epithelial cells in vitro. Cell Biology International, 19: 223231.

35. Vakil R (1961). Cardiovascular involvement in tropical eosinophilia. British Heart J ournal, 23: 576-586. 
36. Walloopillai NJ (1975). Primary pulmonary hypertension, an unexplained epidemic in Sri Lanka. Pathology and Microbiology, 43: 248-250.

37. J ohny K \& Ananthachari M (1965). Cardiovascular changes in tropical eosinophilia. American Heart J oumal, 69: 591-598.

38. Singh M, Sharma S \& Patney R (1974). Tropical eosinophilic pericarditis. Indian Heart J oumal, 26: 261-263.

39. Maizels RM \& Denham DA (1992). Diethylcarbamazine (DEC): immunopharmacological interactions of an anti-filarial drug. Parasitology, 105: S49-S60.

40. Kitchen LW, Hemandez JE \& Zarraga AL (1995). Diethylcarbamazine treatment of chronic osteomyelitis. Complications in Orthopedics, 10: 47-49.

41. Kitchen LW, Ross JA, Turner GJ , Hernandez JE \& Mather FJ (1995). Diethylcarbamazine enhances blood microbial activity. Advances in Therapy, 12: 22-29.

42. Nelson P, Sellon R, Novotney $C$, Devera C, Davidian M, English R, Tompkins M \& Tompkins W (1995). Therapeutic effects of diethylcarbamazine and 3'-azido-3'deoxythymidine on feline leukemia virus lymphoma formation. Veterinary Immunology and Immunopathology, 46: 181194.

43. J oe LK (1962). Occult filariasis: Its relationship with tropical pulmonary eosinophilia. American J ournal of Tropical Medicine and Hygiene, 11: 646-652.

44. Bonne C (1939). Over hypereosinophilie in de milt gecombineerd met een filariainfectie. Geneeskundig Tijdschrift voor Nederlandsch-Indie, 79: 874-876.

45. Klion AD, Massougbodji A, Sadeler BC, Ottesen EA \& Nutman TB (1991). Loiasis in endemic and nonendemic populations: immunologically mediated differences in clinical presentation. J ournal of Infectious Diseases, 163: 1318-1325.

46. Spry CJ (1981). Alterations in blood eosinophil morphology, binding capacity for complexed IgG and kinetics in patients with tropical (filarial) eosinophilia. Parasite Immunology, 3: 1-11.

47. Dhayagude RG (1945). Microfilarial granuloma of the spleen. Observations in twelve additional cases. Archives of Pathology, 40: 275-279.

48. Piyaratn P \& Pradatsundarasar A (1961). Microfilarial granuloma of the spleen. American J ournal of Tropical Medicine and Hygiene, 10: 839-842.

49. Gilbert HM \& Hartman BJ (1996). Short report: a case of fibrosing mediastinitis caused by Wuchereria bancrofti. American J ournal of Tropical Medicine and Hygiene, 54: 596-599.

50. Schuurkamp GJ, Kereu RK, Bulungol PK, Kawereng A, Popon WH, Crane GG, Greenidge J \& Spicer PE (1992). Diethylcarbamazine in the control of splenomegaly associated with bancroftian filariasis in the Ok Tedi area of Papua New Guinea. Transactions of the Royal Society of Tropical Medicine and Hygiene, 86: 531-536.

51. Hoffman SL, Piessens WF, Ratiwayanto S, Hussein PR, Kurniawan L, Piessens PW, Campbell J R \& Marwoto HA (1984). Reduction of suppressor T lymphocytes in the tropical splenomegaly syndrome. New England J oumal of Medicine, 310: 337-341.

52. Wartman WB (1944). Filariasis in American armed forces in World War II. Medicine, 26: 333-394.
53. Englehom TD \& Wellman WE (1945). Filariasis in soldiers on an island in the South Pacific. American J oumal of Medical Sciences, 209: 141-152.

54. Dondero TJ, Mullin SW \& Balasingam S (1972). Early clinical manifestations in filariasis due to Brugia malayi: observations on experimental infections in man. Southeast Asian J oumal of Tropical Medicine and Public Health, 3: 569-575.

55. Acton HW \& Rao SS (1930). Urticaria due to filarial toxin. Indian Medical Gazette, 65: 130-132.

56. Michael P (1945). Filariasis: histopathologic study. United States Naval Medical Bulletin, 45: 225-236.

57. Nutman TB, Miller $K D$, Mulligan $M \&$ Ottesen EA (1986). Loa loa infection in temporary residents of endemic regions: recognition of a hyperresponsive syndrome with characteristic clinical manifestations. J ournal of Infectious Diseases, 154: 10-18.

58. Petralanda I, Yarzabal L \& Piessens WF (1988). Parasite antigens are present in breast milk of women infected with Onchocerca volvulus. American J oumal of Tropical Medicine and Hygiene, 38: 372379.

59. Steel C, Guinea A, McCarthy J $S$ \& Ottesen EA (1994). Long-term effect of prenatal exposure to matemal microfilaraemia on immune responsiveness to filarial parasite antigens. Lancet, 343: 890-893.

60. Ottesen EA, Duke BOL, Karam M \& Behbehani K (1997). Strategies and tools for the control/elimination of lymphatic filariasis. Bulletin of the World Health Organization, 75: 491-503. 